\title{
Los juegos bélicos de Roberto Bolaño
}

\author{
Bojana KovačEvić Petrović \\ Departamento de Lenguas Romances \\ Universidad de Novi Sad \\ bojanakp@ff.uns.ac.rs
}

\begin{abstract}
RESUMEN
En este trabajo investigaremos la presencia de la Segunda Guerra Mundial, las deformaciones del nazismo y la estrategia bélica como temas obsesivos de Roberto Bolaño desde los principios de su carrera literaria hasta las novelas publicadas tras su muerte. Prestando atención a sus juegos literarios y haciendo un análisis detallado de La literatura nazi en América (1996) y El Tercer Reich (la novela empezada en los años ochenta bajo el título La Estrategia Mediterránea pero publicada en 2010, siete años después del fallecimiento del escritor), consultando los artículos escritos por Roberto Bolaño y sobre él, las entrevistas y otros testimonios disponibles, intentaremos mostrar el impacto de la guerra tanto en su vigor literario como en su vida privada, e identificaremos los juegos de guerra como metáfora de la literatura y la vida del escritor chileno, aficionado a los wargames y propietario de una gran colección de ellos.
\end{abstract}

Palabras clave: Roberto Bolaño, La literatura nazi en América, El Tercer Reich, wargames, juegos de guerra.

\section{The wargames of Roberto Bolaño}

\begin{abstract}
In this paper we have investigated the presence of the World War II, the deformations of Nazism and the war strategy as obsessive themes of Roberto Bolaño from the beginning of his literary career to the novels published after his death. Focusing on his literary games and analyzing Nazi Literature in America (1996) and The Third Reich (started in the eighties under the title The Mediterranean Strategy but published in 2010, seven years after the death of the author), referring to the articles written by Roberto Bolaño and about him, as well as to the interviews and other available evidences, we have tried to show the impact of war both in his literary vigor as in his private life, and to identify war games as a metaphor for the literature and life of the Chilean writer, fond of wargames and owner of a large collection of them.
\end{abstract}

Keywords: Roberto Bolaño, Nazi Literature in America, The Third Reich, wargames. 


\section{Reflexiones introductorias: guerra, dictadura y literatura en la obra de Roberto Bolaño}

El escritor chileno Roberto Bolaño (1953-2003) jugó sabiamente con todos los géneros literarios, moviendo los límites de la literatura y dejando huella en escritores de ambas orillas de Atlántico. Se considera que Bolaño dio por terminado (aunque no intencionadamente) el síndrome del Boom, y «al obtener con Los detectives salvajes (Barcelona, 1998) el Premio de Novela Rómulo Gallegos ganó también el reconocimiento como uno de los más valiosos de todo el continente» (Oviedo 2004: 458-459). Asimismo, «no other Latin American author after the Boom of the 1960s has received so much praise and international attention as Roberto Bolaño» (Burgos 2013: 8013).

Autor de más de una veintena de libros, empezó su carrera literaria en México, donde vivía entre 1968 y 1977, con un breve regreso a Chile en 1973 para apoyar a Salvador Allende. En esa época escribía poesía ${ }^{1}$ y con diecinueve poetas rebeldes fundó una «ética en verso» y una «decisión» llamada el Infrarrealismo que en su Manifiesto proponía «dejarlo todo nuevamente y lanzarse a la calle» (VV.AA. 2013: 16).

En el presente trabajo nos concentraremos en la presencia de la Segunda Guerra Mundial, las deformaciones del nazismo y la estrategia bélica como los temas obsesivos de Roberto Bolaño, sobre todo en sus dos novelas: La literatura nazi en América (1996) y El Tercer Reich (empezada en los años ochenta bajo el título La Estrategia Mediterránea, pero publicada en 2010); igualmente consultaremos Estrella distante $^{2}$ (1996), Los detectives salvajes (1998), Nocturno de Chile (2000) y 2666 (edición póstuma de 2004), varios artículos escritos por Roberto Bolaño y sobre él, las entrevistas y otros testimonios disponibles, con la intención de mostrar el impacto de la guerra en la vida y la obra del escritor chileno. En este artículo nos propondremos analizar la presencia de la Segunda Guerra Mundial como el símbolo bolañesco del mayor horror humano, el genocidio y la destrucción, pero también, a través del alter ego del escritor entretejido en los personajes de sus novelas, identificaremos los juegos de guerra como metáfora de la literatura y la vida del escritor chileno, muy aficionado a los tableros y fichas de los wargames, especialmente uno llamado El Tercer Reich, homónimo de una de las novelas que tratamos.

${ }^{1}$ Durante toda la vida Bolaño se consideró un poeta. Es autor de siete libros de poesía, de los cuales el primero, Gorriones cogiendo altura, escrito en 1975 junto con el poeta mexicano Bruno Montané, nunca fue publicado, y el último, su antología personal que abarca unos poemas inéditos, titulado La universidad desconocida y publicado en 2007, se considera el testamento definitivo del autor, suma de su poética o «una última broma de Bolaño - un guiño contra la muerte a través de la propia literatura» (Palma Castro 2010: 1835).

2 En esta novela, que es una ampliación o un hipertexto de la Literatura nazi..., Bolaño introduce el personaje de Arturo Belano, su alter ego, no como el detective salvaje sino como el narrador que persuade al autor (personaje llamado R. B.) a contar la historia de Carlos Wieder, teniente-poeta que escribía versos en el aire con el humo del avión de la Fuerza Aérea en la época de la dictadura de Pinochet y exhibía fotos de las mujeres que había asesinado. Belano es también el protagonista de la novela más elogiada de Bolaño, Los detectives salvajes (1998). 
Investigando la omnipresencia de la guerra en la literatura de Roberto Bolaño, nuestro artículo pretende mostrar que los juegos bélicos también le sirvieron al escritor latinoamericano para jugar con su estrategia narrativa y mejorarla. En uno de los libros publicados después de su muerte y editado por Ignacio Echevarría, Entre paréntesis (ensayos, artículos y discursos 1993-2003), el autor chileno suma su poética literaria y la relación con su propia literatura con las siguientes palabras: «En mi cocina literaria ideal vive un guerrero al que algunas veces (voces sin cuerpo ni sombra) llaman escritor. Este guerrero está siempre luchando» (2004: 323), y él además: «Sabe que al final, haga lo que haga, está derrotado. Sin embargo recorre la cocina literaria, que es de cemento, y se enfrenta a su oponente sin dar ni pedir cuartel» (2004: 323). La esencia de su creación artística siempre estaba directamente relacionada con la noción de la guerra, presente en casi toda su obra y culminada en 2666 cuando Benno von Archimboldi «encuentra su destino como escritor durante la segunda guerra mundial» (Paz Soldán 2008: 19) y donde Bolaño utiliza «las más de doscientas mujeres muertas en los últimos años en Ciudad Juárez -crímenes todavía impunes- no solo como símbolo de la violencia en América Latina post-dictatorial, sino como metáfora del horror y el mal en el siglo XX» (Paz Soldán 2008: 19). De hecho, la imagen de un «libro de geometría colgado de un tendero de ropa en Santa Teresa -imagen de Ciudad Juárez- emblematiza la tensión (y yuxtaposición) en las obras de Roberto Bolaño entre el intelecto y la vida salvaje, o entre las dimensiones civilizadas y bárbaras de la cultura» (López-Vicuña 2009: 200). A lo largo de su narrativa Bolaño reflexiona sobre el horror de las dictaduras, visto desde la perspectiva de América Latina de los años setenta, y lo hace de manera más explícita en sus novelas Estrella distante (1996) -reflexionando sobre «Chile desde y a través del fascismo» (López-Vicuña 2009: 206) - y Nocturno de Chile (2000) -donde «lleva la incomodidad o malestar en la literatura un paso más allá, narrando por así decirlo desde el interior del fascismo» (López-Vicuña 2009: 208). En estas novelas la narrativa de Bolaño «produce un juego de la irrepresentabilidad construyendo una determinada relación política en el nivel ideológico del texto» (Figueroa Jofré 2010: 9984) o en otras palabras: «el Golpe de Estado es puesto en correspondencia necesaria con el nazismo, lo que explica en gran medida la visión de continuidad en la historia de terror» (2010: 9993). Es evidente que «Bolaño escribía con una rapidez vertiginosa» (Mančić 2012), pero en su obra también es obvio que «el monstruo de la violencia acelerada es inigualable» (Mančić 2012).

\section{La literatura nazi en América o el juego bélico-literario}

Roberto Bolaño fue un excelente conocedor de la Segunda Guerra Mundial y el nazismo lo consideraba el peor de todos los males de la historia, una «arquitectura perfecta del mal» (Figueroa Jofré 2010: 9734) y un «modelo del mal radical» (2010: 9632), pero «in his narrative there is a view of violence that does not pretend to instruct us nor resolve the enigmas it has presented» (Burgos 2013: 8242). Una de las obras más originales que escribió tratando ese tema es La literatura nazi en América (1996), que podríamos caracterizar como una antología ficticia, una bibliografía 
de autores inexistentes o un catálogo ${ }^{3}$ de los poetas y las poetisas latinoamericanos relacionados con la ideología fascista, que a veces parecen figurinas perfectas para un juego (bélico) de tabla ${ }^{4}$. Esa novela «juega con la realidad y la ficción y adopta el formato de un diccionario o manual de autores filo-nazis, con un tono entre filológico-erudito, enciclopédico y pseudobiográfico, que hace más obvia la parodia literaria y política» (Bruña Bragado 2010: 8987). En la entrevista dada a Cristián Warnken en la Feria de Libros en Santiago de Chile en 1999, Bolaño comentó que «la literatura es el protagonista principal de la novela» (20'00") donde «los escritores [...] son una metáfora del oficio del escritor, de la literatura» (15'40"), y «ellos encarnan la parte de la locura cotidiana» $\left(18^{\prime} 45^{\prime}\right.$ ") pero admitió que «sin embargo, como autor, creador de esos personajes, yo siento mucha simpatía por ellos» (19'30"). Cuando Warnken quiso comparar su novela con Rayuela de Julio Cortázar, Bolaño comentó que al menos ha intentado «meterse por estructuras, y por juegos dentro de esa estructura» (25'50").

En cuanto a los poetas y los artistas inventados, parece que a través de la metaestrategia bolañesca cada personaje tenía su propia táctica para la vida y el arte. Además, casi ninguno de los 26 poetas y 4 poetisas de la novela tiene cónyuge ni hijos, y casi todos tenían discreto o nulo éxito de crítica y de público. Bolaño en esta novela juega incluso con los nombres de sus protagonistas y con sus años de nacimiento y muerte, dado que ocho personajes murieron o van a morir en el siglo XXI: Segundo José Heredia (1927-2004), Carlos Hevia (1940-2006), Harry Sibelius (19492014), Argentino Schiaffino, alias El Grasa (1956-2015), Gustavo Borda (19542016), Rory Long (1952-2017), Zach Sodenstern (1962-2021), Willy Schürholz (1956-2029) $)^{5}$. Es significativo mencionar que en el Epilogo para monstruos Bolaño

${ }^{3}$ En la novela 2666 Bolaño volverá a hacer un catálogo, pero de muertos. El genocidio documentado es una de las formas de la segunda mitad del siglo XX. En la novela póstuma de Roberto Bolaño el lector es testigo de varios campos de batalla, diferentes estrategias, excomulgación de los judíos por los nazis, enfermedades mentales, locura, pobreza, asesinatos de las mujeres del pueblo mexicano Santa Clara, un peligro del que nadie puede escapar.

${ }^{4}$ Braithwaite nos advierte que la genealogía de la Literatura nazi... tiene una historia muy larga, que va hacia La sinagoga de los iconoclastas de Rodolfo Wilcock, Historia universal de infamia de Borges, Retratos reales e imaginarios de Alfonso Reyes y al final Vidas imaginarias de Marcel Schwob (2006: 42).

${ }^{5}$ Otro tema interesantísimo que querríamos mencionar es otro juego creativo de Bolaño: las muertes de los escritores inventados, imaginadas y relatadas con vigor y minucidad, y frecuentemente escritas desde el futuro. Por ejemplo, Luz Mendiluce Thompson «a mitad de camino se estrella contra una gasolinera. La explosión es considerable» (2010: 36), a Luiz Fontaine da Souza la muerte la sorprenderá «en su confortable piso de Leblon, en Río, mietras escucha el disco del compositor argentino Tito Vázquez y observa por los ventanales el atardecer carioca, los coches, la gente que discute en las aceras, las luces que se encienden, se apagan...» (2010: 60), a Max Mirebalais «la muerte lo encontró trabajando en la obra póstuma de sus heterónimos» (2010: 142), Jim O’Bannon «conservó hasta el final su desprecio por los judíos y por los homosexuales, aunque a los negros poco a poco comenzaba a aceptarlos cuando le llegó la muerte» (2010: 148), Rory Long «tuvo una salud de hierro hasta un mediodía de marzo del año 2017 en que un joven negro llamado Baldwin Rocha le voló la cabeza» (2010: 154) y Argentino Schiaffino, alias El Grasa, «en 2015 abandona Nueva Orleans por causas desconocidas y pocos meses después uno o varios desconocidos lo matan en el patio trasero de un garito de Detroit» (2010: 185). 
ofrece una lista de nombres relacionados con los personajes de la novela: filósofos nazis, historiadores, pintores, escultores, dramaturgos, presentadores y poetas, entre los cuales dos poetisas fueron «asesinadas por la dictadura» (Bolaño 2010: 224-225).

Como hemos mencionado, el juego bolañesco siempre está relacionado con la literatura. Su preocupación esencial son dos posibles maneras de acceder a la clase alta de la sociedad: «mediante la violencia abierta [...] o mediante la literatura, que es una forma de violencia soterrada y que concede respetabilidad en ciertos países jóvenes y sensibles es uno de los disfraces de la escala social» (Bolaño 2010: 135). En cualquier caso, al autor chileno le preocupa qué pasa «cuando la Poesía la hagan los no-poetas y la lean los no-lectores» (Bolaño 2010: 208), y afirma que «Cuando hablo de los escritores nazis en América, en realidad estoy hablando de un mundo a veces heroico, muchas veces canalla, de la literatura en general» (Braithwaite 2006: 112).

La literatura nazi en América cuenta con una larga lista de referencias a los escritores y autores particulares, especialmente poetas ${ }^{6}$, entre los cuales figura el propio Bolaño (2010: 213). Desde luego, aparte de los escritores auténticos que Bolaño nombra dentro de la novela, hay también muchos ficticios, creados de la manera más convincente e inteligente, pero incapacitados para vivir fuera de la creación de su autor. Para ilustrar la gran virtud que Bolaño utiliza para las pseudobiografías de los «autores nazistas», destacaremos algunos de ellos: Juan Mendiluce Thompson se consideró falangista, antinorteamericano, anticapitalista, luego se hizo peronista y ocupó altos cargos políticos (2010: 26); Luz Mendiluce fue una niña preciosa y rozagante, una adolescente gorda y pensativa y una mujer alcohólica y desdichada; la famosa foto de Hitler sosteniendo a la niña de pocos meses le acompañó toda su vida (2010: 28); Ignacio Zubieta era el único hijo varón de una de las mejores familias de Bogotá, buen estudiante, extraordinario deportista, excelente conocedor de la literatura clásica española... y se enroló como voluntario en el ejército franquista (2010: 39, 41); Jesús Fernández Gómez: la cercanía física al poder le

${ }^{6}$ La lista de los escritores que Bolaño menciona en La literatura nazi en América además de ser impresionante ofrece un panorama amplio de la Literatura Universal: Edgar Allan Poe (2010: 18), Cortázar, Borges, Bioy Casares, Mujica Lainez, Ernesto Sábato, Leopoldo Marechal, Stevenson, Conrad (27), Baudelaire, Mallarmé, Claudel, Valéry, Sor Juana Inés de la Cruz (29), Dylan Thomas (30), Corbière, Catulle Mendés, Laforgue, Banville, Fichte, Schlegel, Schelling, Schleirmacher (53), Alfonso Reyes (54), Voltaire, Diderot, D’Alembert, Montesquieu, Rousseau, Hegel, Marx, Feuerbach (57), Kant, Hölderlin, Tieck (58), Sartre (59), Husserl, Heidegger (60), Kafka, Lezama Lima (61), Eliseo Diego, Cintio Vitier, Scholojov (62), Campoamor, Espronceda (69), Virgilio Piñera (63), Julio Verne (73), Vargas Llosa a través de su pueblo natal Arequipa (76), Salazar Bondy (77), Juana de Ibarbourou, Alfonsina Storni (94), Göethe, Jünger, Montaigne, Pascal (98), Conan Doyle (122), Tolstoy a través su novela Guerra y paz, Hemingway (129), Faulkner, Gertrude Stein, Gore Vidal, Dos Passos, Capote, Patricia Highsmith, Hammet, Vonnegut, Fitzgerald, Robert Frost, Wallace Stevens (130), Apollinaire (136), Ginsberg, Corso, Kerouac, Snyder, Ferlinghetti (145), Sandburg (147), Ezra Pound, William Carlos Williams (149), Donne, Robert Browning, Archibald McLeish (150), Zene Gray, Mark Twain (158), Conrad Aiken (160), Adamov, Genet, Grotowski, Copi, Savary (171), Lorca (173), Joyce Masnour, Sylvia Plath, Alejandra Pizarnik (191), Alain Jouffroy, Denis Roche, Marcelin Pleynet, Michel Bulteau, Matthieu Messagier, Claude Pelieu, Franck Venaille, Pierre Tilman, Daniel Biga (192), Victor Hugo, Balzac, Stendhal, Chateaubriand, Flaubert, Lamartine, Musset (207), Bruno Schulz (211), Macedonio Fernández (218), Charles Olson, Robert Lowell, W. S. Mervin, Kenneth Rexroth (221), Pablo Neruda, Nicanor Parra, Enrique Lihn (231). 
conmueve hasta las lágrimas. [...] La Guerra Civil Española es el momento de la verdad. Se dedicó a ella con entusiasmo y valor (2010: 47); Silvio Salvático propuso la reinstauración de la Inquisición, los castigos corporales públicos, la guerra permanente ya sea contra los chilenos o contra los paraguayos... como una forma de gimnasia nacional (2010: 55), Ernesto Pérez Masón en 1965 publicó una novela cuyas primeras letras de cada capítulo componen un acróstico: VIVA ADOLF HITLER. El escándalo fue mayúsculo (2010: 62), Gustavo Borda medía a duras penas un metro cincuenta y cinco centímetros, era moreno, de pelo negro... Sus personajes, por el contrario, son altos, rubios, de ojos azules (2010: 117).

Sin embargo, la biografía apócrifa que les resultó más interesante a los investigadores de La literatura nazi en América es la de Carlos Ramírez Hoffman, El infame, el personaje encarnado en la figura de Carlos Wieder de Estrella distante. Las dos versiones del mismo personaje están relacionadas con el golpe militar del Estado de Chile en 1973 y personifican la dictadura chilena. Los capítulos, además, empiezan respectivamente casi de la misma manera: «La carrera del infame Ramírez Hoffman debió comenzar en 1970 o 1971, cuando Salvador Allende era presidente de Chile» (el último capítulo de La literatura nazi..., 2010: 189) y «La primera vez que vi a Carlos Wieder fue en 1971 o tal vez en 1972, cuando Salvador Allende era presidente de Chile» (primer capítulo de la Estrella distante, 1996: 6).

Aunque Bolaño demuestra su buen conocimiento de la Segunda Guerra Mundial en varias novelas que escribió, queremos destacar el capítulo sobre Willy Schürholz, la «biografía» de uno de «dos alemanes en el fin del mundo» de La literatura nazi en América, quien nació en la Colonia Renacer chilena, a cuarenta kilómetros de Temuco, donde «todos, sin excepción, eran alemanes» (2010: 100) cuya «llegada a Chile coincidió con el fin de la Segunda Guerra Mundial» (2010: 101). Bolaño proyecta incluso la posibilidad de la presencia oculta de Eichman, Bormann y Mengele en la Colonia, y habla sobre la «infancia regida por una férrea disciplina familiar» (2010: 101) de Schürholz, quien en su segunda serie de poemas exhibió una serie de «planos de campos de concentración de Terezin, Mauthausen, Auschwitz, BergenBelsen, Buchenwald y Dachau» (2010: 103) a propósito de reinstaurarlos en Chile. Asimismo, Schürholz publica un inesperado libro infantil «bajo el inútil seudónimo de Gaspar Hauser ${ }^{7} \gg$ (2010: 105), como referencia de otro alemán, cuyo nombre obtuvo el síndrome que padecen los niños que crecen durante mucho tiempo sin afecto paternal o contacto con otras personas.

\section{El Tercer Reich o la estrategia (im)perfecta}

El Tercer Reich es una de las novelas de Roberto Bolaño menos investigadas, a pesar de abarcar todos los elementos bolañescos y una trama bien pensada y desarro-

${ }^{7}$ Kaspar Hauser (1812?-1833), niño salvaje cuya vida sigue llena de misterios. La vida de Schürholz es muy similar, «de extrema pobreza y soledad. No tiene amigos, ni se le conocen novias, rehúye el trato con la gente...» (Bolaño 2010: 102). 
llada. Además, es el territorio literario donde el autor chileno de manera directa entremezcla el juego y la vida real, o los horrores de la Segunda Guerra Mundial y la pesadumbre de lo cotidiano. Por su parte, en El Tercer Reich Bolaño junta sus dos pasiones: la de los juegos de mesa y la de la investigación detectivesca. El autor chileno empezó a escribir esta novela en los años ochenta, la acabó en $1989^{8}$ bajo el título $L a$ Estrategia Mediterránea, pero el libro fue publicado 21 años más tarde y siete años después del fallecimiento del escritor, en 2010. Escrito en forma de diario (entre el 20 de agosto y el 30 de septiembre, todos los días salvo 13, 15, 16, 26, 27, 28 y 29 de septiembre y con cierto epílogo escrito el 20 de octubre), El Tercer Reich abarca todos sus temas y obsesiones preferidos, incluida la desolación que dejaron las dictaduras latinoamericanas, la violencia y el nazismo, o «la necesidad de articular memoria y justicia, que en El Tercer Reich se instala en el terreno de lo lúdico y en un plano simbólico que es la literatura -la escritura misma» (Aguilar 2013: 186).

Aficionado de los juegos de guerra y campeón alemán del juego estratégico sobre la Segunda Guerra Mundial El Tercer Reich, Udo Berger (2013: 25) veranea con su novia Ingeborg 9 en un pequeño hotel de un lugar desconocido de la Costa Brava (donde como adolescente veraneaba con sus padres), gestionado por una bella y enigmática alemana, Frau Else. Allí instala en su habitación una gran mesa para su juego favorito y obsesivo (y al final prestado para el título de la novela), donde fantasea nuevas estrategias en su tablero de hexágonos y realiza la batallas militares de la Segunda Guerra Mundial con sus fichas de regimentos, y prefiere jugar a cualquier otra cosa: «Yo no fui a la playa. Me quedé en la habitación -si bien a cada rato me asomaba al balcón o a la ventana- revisando mi abandonado juego» (Bolaño 2013: 74). La novela es, como hemos dicho, su diario escrito en primera persona, donde el protagonista cuenta los acontecimientos ocurridos en el hotel catalán, en el cual Udo e Ingeborg conocen a otra pareja alemana -Charly y Hanna-, dos españoles con apodos Lobo y El Cordero y un hombre llamado El Quemado por su cuerpo deformado por un incendio. Cuando Charlie desaparece la novela se nubla de inquieta atmósfera de suspense y de latente malestar que se perseverará hasta el final.

Apasionado jugador, Udo explica a Hanna que «Este tablero, como puedes apreciar, es el mapa de Europa. Es un juego. También es un desafío. Y es parte de mi trabajo» (2013: 95). Pero al perder el trabajo, el dinero y la vida anterior, Udo irá cambiando su visión del mundo para concluir que «todos nosotros éramos como fantasmas que pertenecían a un Estado Mayor fantasma ejercitándose continuadamente sobre tableros de wargames» (2013: 356). Resulta interesante que Udo siempre lleva consigo un bloc de notas para apuntar las ideas de su futura estrategia, de la misma manera que la mayoría de escritores lo lleva en el bolsillo para apuntar ideas para el próximo libro.

\footnotetext{
${ }^{8}$ Fue escrita a mano, y antes de morir, el autor chileno había pasado a ordenador unas 60 páginas. La dedicó a su esposa, Carolina López.

${ }^{9}$ La novia de Archimboldi en 2666 tiene el mismo nombre.
} 
Rise and Decline of the Third Reich ${ }^{10}$ es una simulación realista de grandes situaciones ocurridas en Europa durante la Segunda Guerra Mundial. Aparte de varias descripciones del juego estratégico y las tácticas usadas, con una descripción detallada de los métodos, hexágonos y fichas $(2013: 96,97,115,175,176,189,212$, 213, 220, 221, 222, 223, 247, 248, 249, 282, 283, 284 y 285), en la página 295 de $E l$ Tercer Reich (2013) Bolaño nos confirma que se trata precisamente de su juego preferido: «[...] Las letras y los colores anaranjados de la caja resultaban perfectamente visibles y familiares: era el Tercer Reich, mi Tercer Reich. ¿Qué hacía el Quemado, a esas horas, con mi juego?». Por otro lado, en las reflexiones sobre la literatura chilena publicadas en Entre paréntesis, Bolaño nos descubre su incomodidad creciente hacia los games: «Mis pasos me llevan, sin que me lo proponga, hasta una tienda de juegos. [...] La mayoría son jóvenes en busca de videojuegos. Cada vez me siento peor» (2004: 116).

Como hemos dicho, el mismo Bolaño fue un apasionado jugador de los wargames de tablero ${ }^{11}$; su juego favorito era precisamente El Tercer Reich y en su casa de Blanes se conserva una importante colección de los juegos de mesa ${ }^{12}$. En 2003 el director Jaume Pujadas hizo un documenta ${ }^{13}$ sobre el escritor chileno, conversando con sus amigos y cómplices de juegos de guerra, ofreciéndonos la prueba palpable de su gran pasión. Además, en varias ocasiones a través de El Tercer Reich reconocemos a Bolaño y su afición: «A mí los soldaditos de plomo no me interesan demasiado... [...] Prefiero los juegos de tablero» (2013: 80), «no había tenido la oportunidad de hablar de wargames con nadie. Un jugador siempre me entendería. Para nosotros es un placer hablar de juegos» (2013: 81) -lo que nos confirman los amigos de Bolaño entrevistados en el documental de Pujadas-, «me levanté, me di una ducha y me encontré en el juego» (2013: 96). El juego de Udo / Roberto podríamos entenderlo como un refugio, una solución o un escape del absurdo y de la mediocridad, porque lo único que importa es la vida (2013: 296). A través de la minuciosa estrategia del autor de la novela, el juego de mesa se convierte en protagonista, «tornándose cada vez más complejo, pasando de entrenamiento y diseño de una estrategia a una partida real» (Peñaloza 2011: 285) y el texto se vuelve «un tablero cuadriculado, una abstracción alejada de toda particularidad, un desplazamiento hacia la universalidad, un discurso que permanece inmóvil a medida que avanza» (Peñaloza 2011: 287), hasta que el partido termine y las fichas se agoten. En el momento cuando el juego deja de ser la vida y la vida se vuelve el juego, el protagonista derrotado deja de tener ganas de jugar.

${ }^{10}$ El juego fue creado en 1974 de parte de John Prados y lanzado por Avalon Hill Games Inc., y la nueva versión llamada Advanced Third Reich apareció en 1992. Véase la descripción detallada en: http://mapandcounters.blogspot.rs/2010/05/tahgc-third-reich-4th-ed-19741981.html

11 Véase http://www.latercera.com/contenido/1453_220197_9.shtml y http://www.lavanguardia.com/ cultura/20101219/54091163845/la-viuda-del-escritor-carolina-lopez-roberto-bolano-tuvo-tiempo-dedisfrutar-el-reconocimiento.html

12 Véase http://www.elmundo.es/elmundo/2010/01/27/cultura/1264611499.html

13 Véase https://vimeo.com/42254777 


\section{El nombre / la figura de Hitler}

En las novelas de Roberto Bolaño la figura de Hitler está relacionada con literatura, y no con nazismo como ideología. En otras palabras, los escritores nazis que protagonizaron la novela La literatura nazi en América tienen como canon su propia escritura. En la biografía de Edelmira Thompson de Mendiluce, el escritor relata que «Edelmira y sus hijos son presentados a Adolf Hitler, quien cogerá a la pequeña Luz y dirá «Es sin duda una niña maravillosa»» (2010: 16) Así, Hitler «causa en la poetisa argentina una gran impresión» y sugiere a sus hijos «un internado suizo, aunque apostilla que la mejor escuela es la vida». Luego, en la biografía de su hija, nos damos cuenta de que la muchacha a veces «explicaba que se trataba de una sobrina de Hitler» (2010: 28) y que unos años después escribió «su famoso poema Con Hitler fui feliz» (2010: 30) y se elogiaba con «la foto de su primera infancia en donde aparece con Hitler» (2010: 34). Por otro lado, Ernesto Pérez Masón, «novelista realista, naturalista, expresionista, cultor de decadentismo y del realismo socialista, autor de una veintena de obras que avala una carrera que se inicia con el espléndido relato Sin Corazón» (2010: 61) provocó un escándalo con su novela $\mathrm{La}$ Sopa de los Pobres, donde Sholojov «narra los sufrimientos de una familia numerosa de La Habana de 1950» (2010: 62), porque las primeras letras de cada uno de los quince capítulos componen el mencionado acróstico: VIVA ADOLF HITLER. En Epílogo para monstruos Bolaño menciona (inventa) a otro personaje, Edelmiro Corozzone (1940-1927), quien «estaba predestinado a llamarse Adolfo por Adolf Hitler» (Bolaño 2010: 219).

Por otro lado, en El Tercer Reich el fantasma del nazismo se presenta como un rostro más de lo monstruoso, frecuentemente presente en las ficciones de Bolaño. Cuando la camarera/sirvienta Clarita le pregunta a Udo: «-¿Eres nazi?», él responde «-No, no lo soy. Más bien soy antinazi. ¿Qué te hace pensar eso, el juego?» (2013: 311).

\section{Reflexiones finales}

Estoy condenado, afortunadamente, a tener pocos lectores, pero fieles. Son lectores interesados en entrar en el juego metaliterario y en el juego de toda mi obra, porque si alguien lee un libro mío no está mal, pero para entenderlo hay que leerlos todos, porque todos se refieren a todos. (Bolaño 2006: 118)

¿Por qué Roberto Bolaño fue el gran renovador de la literatura y por qué compartía esa pasión con los juegos bélicos? Sobre todo porque tuvo un talento extraordinario y un enorme potencial creativo ${ }^{14}$, luego porque movió los límites de la lite-

14 Para entender mejor su vida y su carrera hay que tener en cuenta su poema «Mi carrera literaria», publicado en octubre de 1990: «Rechazos de Anagrama, Grijalbo, Planeta, con toda seguridad / también de Alfaguara, Mondadori. Un no de Muchnick, / Seix Barral, Destino... Todas las editoriales... 
ratura buscando los márgenes de su propia creación literaria jugando con los géneros, los personajes, las estrategias y los temas que le obsesionaban. En medio de los extremos del Boom y todas las tendencias posteriores, Roberto Bolaño se alzó como el único capaz de librarse del peso de los «grandes padres» para crear un nuevo universo literario. Siempre preocupado por en qué consiste la verdadera literatura, cómo se entrelaza con la vida y cuáles son las características de un escritor, Bolaño también estaba obsesionado con la violencia, el pasado y el futuro. Otros temas presentes desde los principios de su carrera literaria hasta las novelas publicadas tras su muerte fueron las deformaciones del nazismo y la estrategia bélica, que podemos percibir en casi toda su obra, pero ese foco es tal vez el más obvio en sus novelas Literatura nazi en América y El Tercer Reich. En el Nocturno de Chile, Los detectives salvajes, Estrella distante y 2666 Roberto Bolaño también aplica la táctica de los juegos estratégicos para construir las historias y formar personajes excepcionales y únicos. Considerando que la vida real a veces se parece demasiado en una pesadilla, Roberto Bolaño ha creado nuevo tipo de monstruo, diferente a los famosos dictadores presentes en centenas de novelas hispanoamericanas. Podríamos decir que el nazismo en su obra está relacionado con literatura (sobre todo con la nueva y mala), con la dictadura en Chile -el país y su cultura han cambiado con el nuevo régimen-, con «el fascismo neoliberal» y con los juegos estratégicos.

La metatextualidad y la intertextualidad de las obras de Bolaño (las conocidas y las todavía desconocidas) ofrecen un amplio campo para las futuras investigaciones, y nuestro artículo es solo un intento de percibir los detalles relacionados con la Segunda Guerra Mundial y sus diversas formas en las novelas de uno de los escritores más importantes de habla hispana en los últimos treinta años. Con ganas de hacer una pequeña contribución y tal vez abrir nuevos caminos de los estudios de su obra, en cada momento hemos tenido en cuenta algo que aprendimos de otro escritor chileno, Alejandro Zambra: que Bolaño es casi infinito y que estamos muy lejos de agotarlo.

\section{Referencias bibliográficas}

AgUiLAR, Paula (2013): Libros de arena, desiertos de horror: La narrativa de Roberto Bolaño. Tesis doctoral: Universidad Nacional de La Plata [en línea]. En: http://www.memoria.fahce.unlp.edu.ar/tesis/te.984/te.984.pdf [19/06/2016].

- (1996): Estrella distante. Barcelona: Anagrama.

- (1999): «La belleza de pensar. Entrevista de Cristián Warnken en la Feria Internacional del Libro de Santiago (Santiago de Chile, 1999)» [en línea]. En: http://garciamadero.blogspot.rs/2010/06/roberto-bolano-en-la-belleza-de-pensar.html $[15 / 06 / 2016]$.

Todos los / lectores... / Todos / los gerentes de ventas... / Bajo el puente, mientras llueve, una oportunidad de oro / para verme a mí mismo: / como una culebra en el Polo Norte, pero escribiendo. / Escribiendo poesía en el país de los imbéciles. / Escribiendo con mi hijo en las rodillas. / Escribiendo hasta que cae la noche / con un estruendo de los mil demonios. / Los demonios que han de llevarme al infierno / pero escribiendo» Bolaño 2007: 7-8). 
- (2004): Entre paréntesis. Ensayos, artículos y discursos (1998-2003). Barcelona: Anagrama.

- (2010): La literatura nazi en América. Barcelona: Anagrama.

- (2013): El Tercer Reich. Barcelona: Anagrama.

BRAITHWAITE, Andrés (ed.) (2006): Bolaño por sí mismo. Entrevistas escogidas. Santiago de Chile: Universidad Diego Portales.

BRUÑa BRAGADO, María José (2010): «Roberto Bolaño: Formas del mal y posiciones intelectuales», en Ríos Baeza, F. A. (ed.): Roberto Bolaño: Ruptura y violencia en la literatura finisecular, pp. 8811-9233. México: Ediciones Eón.

Burgos, Carlos (2013): «Roberto Bolaño», en Corral, W, De Castro, J. E and Birns, N (eds.) (2014): The Contemporary Spanish-American Novel: Bolaño and after, pp. 301-309. New York: Bloomsbury.

FIgUEROA JOFRÉ, Julio Sebastián (2010): «Bolaño con Borges: Juegos con la infamia y el mal radical», en Ríos Baeza, F. A. (ed.): Roberto Bolaño: Ruptura y violencia en la literatura finisecular, pp. 9618-10271. México: Ediciones Eón.

LÓPEZ-VICUÑA, Ignacio (2009): «Malestar en la literatura: Escritura y barbarie en Estrella distante y Nocturno de Chile de Roberto Bolaño». Revista Chilena de Literatura 75, noviembre: $99-215$.

MANČIĆ, Aleksandra (2012): «Volcanes vistos desde Balcanes: Lecturas espodimánticas de unas líneas de Roberto Bolaño» [en línea]. En: http://www.letrasenlinea.cl/?p=2816 [17/06/2016].

OviEDO, José Miguel (2004): Historia de la literatura hispanoamericana 4. De Borges al presente. Madrid: Alianza Editorial.

PALMA CASTRO, Alejandra (2010): «Un poeta latinoamericano en el D. F.: Irrupción poética de Roberto Bolaño», en Ríos Baeza, F. A. (ed.): Roberto Bolaño: Ruptura y violencia en la literatura finisecular, pp.1785-2142. México: Ediciones Eón.

PAZ SOLDÁN, Edmundo (2008): «Roberto Bolaño: Literatura y apocalipsis», en Edmundo Paz Soldán y Gustavo Faverón Patriau: Bolaño salvaje, pp.11-30. Barcelona: Candaya.

PeÑAlozA, Pablo (2011): «El Tercer Reich de Roberto Bolaño». Aisthesis 50: 284-289.

VV.AA. (2013): Nada utópico nos es ajeno (Manifiestos Infrarrealistas). México: Tsunun [en línea]. En: https://tsunun.files.wordpress.com/2013/05/nada-utc3b3pico-nos-esajeno-manifiestos-infrarrealistas1.pdf [22/06/2016]. 